\title{
The crossover design for migraine preventives: an analyses of four randomized placebo-controlled trials
}

\author{
Astrid Bjørke Jenssen ${ }^{1}$, Lars Jacob Stovner ${ }^{1,2}$, Erling Tronvik ${ }^{1,2}$, Trond Sand ${ }^{1,3}$, Grethe Helde ${ }^{1}$, \\ Gøril Bruvik Gravdahl ${ }^{2}$ and Knut Hagen ${ }^{1,2,4^{*}}$ (D)
}

\begin{abstract}
Aims: To evaluate the crossover design in migraine preventive treatment trials by assessing dropout rate, and potential period and carryover effect in four placebo-controlled randomized controlled trials (RCTs).

Methods: In order to increase statistical power, the study combined data from four different RCTs performed from 1998 to 2015 at St. Olavs Hospital, Norway. Among 264 randomized patients, 120 received placebo treatment before and 144 after active treatment.

Results: Only 26 (10\%) dropped out during the follow-up period of 30-48 weeks, the majority $(n=19)$ in the first 12 weeks. No period effect was found, since the treatment sequence did not influence the responder rate after placebo treatment, being respectively for migraine $30.5 \%$ vs. $27.4 \%(p=0.59)$ and for headache $25.0 \%$ vs. $24.8 \%$ ( $p=0.97$, Chi-square test) when placebo occurred early or late. Furthermore, no carryover effect was identified, since the treatment sequence did not influence the treatment effect (difference between placebo and active treatment). There was no significant difference between those who received active treatment first and those who received placebo first with respect to change in number of days per 4 week of headache $(-0.9$ vs. $-1.3, p=0.46)$ and migraine ( -1.2 vs. $-0.9, p=0.35$, Student's t-test).

Conclusions: Summary data from four crossover trials evaluating preventive treatment in adult migraine showed that few dropped out after the first period. No period or carryover effect was found. RCT studies with crossover design can be recommended as an efficient and cost-saving way to evaluate potential new preventive medicines for migraine in adults.
\end{abstract}

Keywords: Headache, Preventive treatment, Carryover effect, Loss of follow-up

\section{Introduction}

Preventive medication is indicated for many migraine patients but used regularly by relatively few [1]. The randomized controlled trial (RCT) is the gold standard for evaluating the effect of preventive treatment in patients with migraine. According to the current guidelines for RCTs of preventive treatment in migraine published in 2012, either a parallel or crossover study design can be used, depending on the trial's objectives [2].

\footnotetext{
* Correspondence: knut.hagen@ntnu.no

'Department of Neuromedicine and Movement Science, Norwegian University of Science and Technology, 7489 Trondheim, Norway

${ }^{2}$ Norwegian Advisory Unit on Headaches, St. Olavs University Hospital,

Trondheim, Norway

Full list of author information is available at the end of the article
}

The guidelines also recommend that a placebo arm always should be included in trials [2], but this has been done in less than $10 \%$ of RCTs evaluating multiple preventive drugs [3]. Summaries of results of RCTs on oral medication for migraine prevention including placebo arms have shown that $21-22 \%$ of patients had at least $50 \%$ reduction of attacks during oral placebo treatment $[4,5]$. Higher responder rates have been found in studies with parallel group design compared with crossover studies [4], possibly because of higher positive expectations in participants in parallel studies than in crossover studies [4].

In contrast to the guidelines for RCTs of drug treatment in migraine, recently published guidelines for 
controlled trials of preventive treatment recommend parallel-group design over crossover design $[6,7]$. The main argument against the crossover design is the possibility of carryover effect even when a washout period is being used. Furthermore, because of the long study period there may be high withdrawal rates and increase in protocol deviations, and marked spontaneous fluctuations in disease activity over time, known as period effects, may occur. The scientific documentation for these arguments is modest. It should be highlighted that the listed reference for these arguments, appearing in the guidelines for chronic migraine [6], was published in 1987 [8], almost 20 years before the diagnosis of chronic migraine was defined [9]. Thus, analytic studies are needed to assess the value of the crossover design for RCTs in migraine preventive medication.

It has been argued that potential carry-over effects will be hard to detect in a single study, in part because the studies are powered to detect a relatively large and clinically meaningful effect. Carry-over effects are likely to be smaller, and the statistical power is much smaller since only half the participants receive the active medication before placebo [10]. Similar arguments can be made about the period effect.

During a period of 20 years, four methodologically very similar randomized placebo-controlled trials in migraine using a crossover design have been performed at St. Olavs University Hospital in Trondheim, Norway [11-14]. The aim of the present study was to evaluate the crossover design for trials on episodic migraine preventive medication by combining the data from these four studies, in this way achieving higher statistical power for assessing dropout rate and potential period and carryover effects.

\section{Methods}

\section{Study design}

Data included in this study was collected from four placebo-controlled RCTs conducted between 1998 and 2015 at the Department of Neurology at St. Olavs University Hospital in Trondheim, Norway [11-14]. All studies included migraine patients with at least two migraine attacks during the last 4 weeks and had a crossover design. In all studies participants kept a headache diary throughout the study and had regular consultations with the study neurologist, and repeated telephone calls by a study nurse. The first three studies evaluated antihypertensive medication (candesartan, lisinopril and propranolol versus candesartan) [11-14], whereas the last published study evaluated a dietary supplement, acetyl-l-carnitine (ALCAR) [14]. In all four studies participants received maximum number of tables in week 2-11, and half dose in week 1 and 12 .

Study details that differ between the studies are summarized in Table 1 . One of the studies had a double crossover design, i.e. comparing candesartan with an active drug (propranolol) in addition to placebo. In the three studies using antihypertensives as active substance [11-13], there was a significant effect of the active substance over placebo. This was not shown in the study using ALCAR as active substance [14]. One important difference between the studies was that placebo tablets were used in the baseline period ("placebo-run-in") and washout period in the two first studies $[11,12]$, but not in the two last ones $[13,14]$. Having a placebo run-in was recommended in the first and second edition of guidelines for controlled trials of drugs in migraine in order to exclude placebo responders $[15,16]$, but not in the third edition [2].

Table 1 Summary of study details which differ between studies

\begin{tabular}{|c|c|c|c|c|}
\hline Authors & Schrader et al. [11] & Tronvik et al. [12] & Stovner et al. [13] & Hagen et al. [14] \\
\hline Publication year & 2001 & 2003 & 2014 & 2015 \\
\hline Number included & $60^{1}$ & $60^{2}$ & 72 & 72 \\
\hline Age range at inclusion & $19-59$ & $18-65$ & $18-65$ & $18-65$ \\
\hline Number of migraine attacks per month at inclusion & $2-6$ & $2-6$ & $\geq 2$ & $\geq 2$ \\
\hline Number of treatment periods & 2 & 2 & 3 & 2 \\
\hline Duration of follow-up, weeks & 30 & 32 & 48 & 32 \\
\hline Active substance(s) & Lisinopril & Candesartan & Candesartan and Propanolol ${ }^{3}$ & Acetyl-L-carnitine \\
\hline Effect of active versus placebo & Yes & Yes & Yes & No \\
\hline Blinding & Double & Double & Triple ${ }^{4}$ & Triple ${ }^{4}$ \\
\hline Placebo tablets in baseline period & Yes & Yes & No & No \\
\hline Placebo tablets in washout period & Yes & Yes & No & No \\
\hline
\end{tabular}


In the double crossover study, there were three treatment periods [13]. Twenty-four patients (intention-to-treat-analysis) got placebo first, 16 got placebo after treatment with one active substance (either candesartan or propranolol), and 21 got placebo after both active substances. Furthermore, two of the studies were run as double blind, and two as triple blind, i.e. not only were participants and study personal blinded, but also the statistician $[13,14]$.

The primary efficacy variables in the two first studies were headache days and migraine days per 4 weeks $[11,12]$, whereas the primary efficacy variables in two last studies was number of days with moderate to severe headache lasting $\geq 4 \mathrm{~h}$ or being treated with attack medication [13, 14]. To make data uniform regarding headache days and migraine, we had to perform a new data entry of all headache diaries for three studies [12-14] $(n=204)$. In the headache diary the participants had to register all headaches. A migraine day was defined as a day with headache the patients themselves considered to be migraine. Number of headache days/month was the sum of migraine days and days with non-migrainous headache. Responders were defined as patients with at least $50 \%$ reduction in headache days or migraine days in the 12-week period compared to baseline. For individuals with incomplete headache diaries, the last-observation-carried-forward strategy was used.

\section{Ethics}

The present study (2017/2050/REK Midt) and all the four original studies [11-14] were approved by the Regional Committee for Ethics in Medical Research, Norway. The two last studies [13, 14] were also approved by the Norwegian Medicines Agency, but this was not needed at the time the two first studies were performed. All participants had signed a written consent declaration in the original studies.

\section{Statistical analysis}

Differences between proportions were analyzed by Chi-squared test including evaluation of dropouts and responder rates.

Period effect (i.e. spontaneous fluctuations in disease activity) was evaluated by comparing the mean number of headache days/migraine days (using Wilcoxon's paired signed rank test) in the 12 weeks on placebo related to whether the placebo period occurred early or late after the patient was included in the study. Furthermore, the period effect was also evaluated by analyzing the placebo response by comparing responder rate for participants who received placebo treatment in the first period compared to those who received placebo after active treatment. To minimize the influence of dropouts, the responder rate in each period was estimated based on eligible participants (number included minus dropouts). The placebo response was also evaluated by comparing days with headache and migraine during baseline with the 12 weeks of placebo-treatment using Wilcoxon's paired signed rank test.

Because placebo tablets were used in the baseline period in the two first studies $[11,12]$, we presented separate data for studies with $[11,12]$ and without placebo $[13,14]$ in the baseline period, as well as merged data from all four studies.

There are no established rules or guidelines on how to calculate potential carryover effect, defined as a prolonged effect of active treatment that persist into the subsequent period [17]. However, if such effect exists, one should expect that treatment sequence, i.e. placebo before active substance or vice versa, would influence the efficacy. By using Student's t-test we evaluated difference in number of days per 4 weeks of headache and migraine between active treatment and placebo according to sequence. In the analyses of carryover effect, we excluded participants included in the last performed study because no effect of active treatment (ALCAR) compared to placebo treatment was found [14]. Another indirect way to evaluate carryover effect was to compare responder rate related to treatment sequence as mentioned above. Finally, the mean number of headache/migraine days in the washout period was compared in relation to treatment sequence, as this period would presumably be even more affected by potential carryover effect.

The SPSS statistical program (version 25) was used for the statistical analyses and two-sided $p$ values less than 0.05 were regarded as statistically significant.

\section{Results}

In the two first studies, a total of 138 migraine patients entered the baseline period using placebo tablets, whereas in the two last studies 164 migraine patients entered the baseline period without using placebo tablets. The proportion of patients that had to leave the study because of too few migraine attacks was not different among those who did and did not use placebo tablets during the baseline period ( $5.8 \%$ versus $6.7 \%, p=0.82$ ).

Baseline characteristics of the 264 randomized individuals in the four studies are summarized in Table 2.

\section{Dropout rates and per protocol completers}

After randomization, 26 out of 264 (9.8\%) dropped out during the follow-up period, the majority $(n=19)$ early in the first 12-week period. During the first period higher dropout rate was found among participants who were randomized to active treatment (16 out of 144) than among those who got placebo treatment (3 out of 120) 
Table 2 Background variables in the different studies

\begin{tabular}{|c|c|c|c|c|c|}
\hline Author & Schrader et al. [11] & Tronvik et al. [12] & Stovner et al. [13] & Hagen et al. [14] & All \\
\hline Publication year & 2001 & 2003 & 2014 & 2015 & - \\
\hline Number included & 60 & 60 & 72 & 72 & 264 \\
\hline Mean age (SD) & $41.1(10.2)$ & $42.9(12.0)$ & $37.3(10.7)$ & $38.9(12.3)$ & $39.9(11.5)$ \\
\hline Female sex, n (\%) & $50(83.3)$ & $47(78.3)$ & $59(81.9)$ & $63(87.5)$ & $219(83.0)$ \\
\hline Migraine with aura, n (\%) & $27(45.0)$ & $28(46.7)$ & $33(45.8)$ & $23(31.9)$ & $111(42.0)$ \\
\hline Mean BMI (SD) & $24.3(4.4)$ & $25.3(4.3)$ & $N A^{1}$ & $24.4(3.7)$ & $24.7(4.1)$ \\
\hline Mean age at first migraine attack (SD) & $17.1(7.7)$ & $19.6(9.1)$ & $17.9(10.7)$ & $20.1(9.3)$ & $18.7(9.3)$ \\
\hline Mean self-reported frequency of migraine attacks/months (SD) & $4.3(1.6)$ & $3.7(1.2)$ & $4.8(3.6)$ & $3.6(1.6)$ & $4.1(2.3)$ \\
\hline Mean migraine days/4 weeks (SD) & $6.6(3.4)$ & $5.7(2.9)$ & $5.3(3.1)$ & $5.3(2.3)$ & $5.7(2.9)$ \\
\hline Mean headache days/4 weeks (SD) & $9.7(5.2)$ & $8.4(3.9)$ & $8.2(4.3)$ & $6.4(2.8)$ & $8.1(4.2)$ \\
\hline
\end{tabular}

${ }^{1}$ Not available

(11.1\% versus $2.5 \%, p=0.008)$. Overall, $208 \quad(79 \%)$ completed the studies per protocol.

\section{Period effect: placebo response related to treatment sequence}

At baseline mean number of headache days tended to be somewhat lower for those who got placebo treatment first $(n=120)$ than for those who got placebo after active treatment $(n=144)$ (overall 7.6 vs. 8.5 days, $p=0.08$ ), whereas migraine days at baseline were nearly identical ( 5.8 vs. 5.6 days, $p=0.68$ ) (Table 3). No significant difference in responder rate was found for individuals who received placebo in the first period compared to those who got placebo after active treatment, the proportions for all four studies being respectively $27.4 \%$ vs. $30.5 \%(p=0.59)$ for migraine days and $24.8 \%$ vs. $25.0 \%(p=0.97)$ for headache days (Table 3). For those who got placebo-treatment in the first period, the number of days per 4 weeks decreased with a mean of 1.4 for migraine (5.8 in run-in versus 4.4, $p<0.001$ ) and 1.7 for headache (7.6 run-in versus 5.9, $p<$ $0.001)$. Correspondingly, for those who got placebo after active treatment the number of days per 4 weeks decreased with a mean of 1.0 for migraine (5.6 in run-in versus $4.6, p<0.001)$ and 2.1 for headache (8.5 run-in versus $6.4, p<0.001$ ) (Table 3). There was no significant difference when comparing the reduction in migraine days during placebo treatment from baseline period related to treatment sequence $(p=0.87)$.

\section{Analyses of carryover effect}

Days per 4 weeks during follow-up according to treatment sequence are presented in Fig. 1 for migraine and Fig. 2 for

Table 3 Number of dropouts and days with headache and migraine per 4 weeks related to treatment sequence and use of placebo in baseline period $(N=264)$

\begin{tabular}{|c|c|c|c|c|c|c|}
\hline \multirow[b]{2}{*}{ Treatment sequence } & \multicolumn{2}{|c|}{ Placebo given in baseline period } & \multicolumn{2}{|c|}{ Placebo not given in baseline period } & \multicolumn{2}{|l|}{ All } \\
\hline & $\begin{array}{l}\text { Placebo in first } \\
\text { period }\end{array}$ & $\begin{array}{l}\text { Active treatment } \\
\text { in first period }\end{array}$ & $\begin{array}{l}\text { Placebo in first } \\
\text { period }\end{array}$ & $\begin{array}{l}\text { Active treatment } \\
\text { in first period }\end{array}$ & $\begin{array}{l}\text { Placebo in first } \\
\text { period }\end{array}$ & $\begin{array}{l}\text { Active treatment } \\
\text { in first period }\end{array}$ \\
\hline Number included & 60 & 60 & 60 & 84 & 120 & 144 \\
\hline Dropouts during first period & 2 & 5 & 1 & 11 & 3 & 16 \\
\hline \multicolumn{7}{|l|}{ Migraine days/month, mean (SD) } \\
\hline Baseline period & $6.0(2.9)$ & $6.2(3.4)$ & $5.5(2.4)$ & $5.2(2.9)$ & $5.8(2.7)$ & $5.6(3.1)$ \\
\hline Placebo treatment period & $5.0(3.0)$ & $5.5(3.2)$ & $3.9(2.2)$ & $3.9(2.7)$ & $4.4(2.6)$ & $4.6(3.0)$ \\
\hline Washout period & $4.6(3.9)^{1}$ & $5.9(4.3)^{1}$ & $3.8(3.1)^{2}$ & $4.0(2.7)^{2}$ & $4.2(3.5)^{2}$ & $4.8(3.6)^{2}$ \\
\hline Number of responders (\% of eligible) ${ }^{4}$ & $16(27.6)^{5}$ & $15(27.3)^{5}$ & $16(27.1)^{5}$ & $24(32.9)^{5}$ & $32(27.4)^{5}$ & $39(30.5)^{5}$ \\
\hline \multicolumn{7}{|l|}{ Headache days/month, mean (SD) } \\
\hline Baseline period & $8.4(3.7)$ & $9.8(5.3)$ & $6.8(3.0)$ & $7.7(4.1)$ & $7.6(3.5)$ & $8.5(4.8)$ \\
\hline Placebo treatment period & $7.0(4.1)$ & $7.4(4.1)$ & $4.9(2.8)$ & $5.7(3.9)$ & $5.9(3.6)$ & $6.4(4.1)$ \\
\hline Washout period & $6.1(4.3)^{3}$ & $9.1(6.5)^{3}$ & $4.5(3.5)^{1}$ & $5.6(4.2)^{1}$ & $5.3(4.0)^{3}$ & $7.1(5.6)^{3}$ \\
\hline Number of responders (\% of eligible) ${ }^{4}$ & $13(22.4)^{5}$ & $13(23.6)^{5}$ & $16(27.1)^{5}$ & $19(26.0)^{5}$ & $29(24.8)^{5}$ & $32(25.0)^{5}$ \\
\hline
\end{tabular}

Washout headache/migraine according to treatment sequence compared by Students t-test: ${ }^{1} P \geq 0.08{ }^{2} P \geq 0.16{ }^{3} P \leq .005$

${ }^{4}$ Responders are defined as having at least $50 \%$ reduction in number of days/month. Eligible is defined as number included minus dropouts

Number of responders related to treatment sequence compared by Chi-square test: ${ }^{5} P \geq 0.47$ 


\section{Migraine days per 4 weeks}

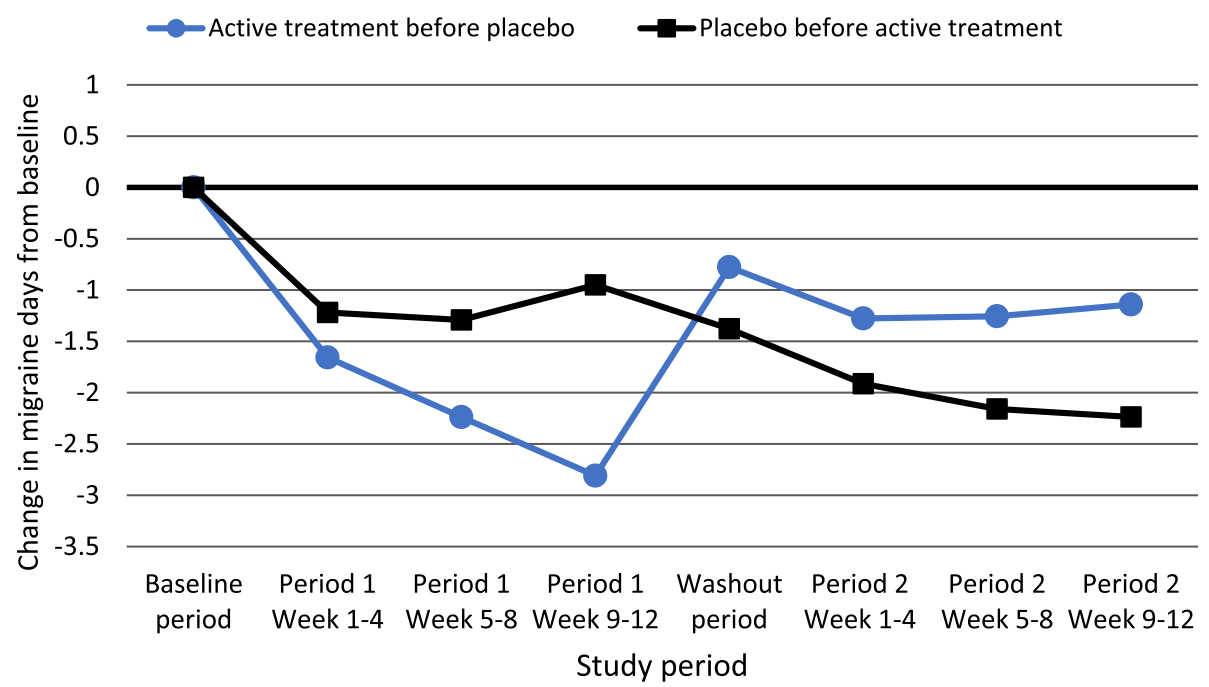

Fig. 1 Migraine days per 4 weeks in relation to treatment sequence (square: Placebo first, $n=80$; circle: Active treatment first, $n=96)$. Data from the study published in 2015 (the ALCAR-study) were omitted from this analysis due to lack of efficacy vs. placebo

headache. As demonstrated, a marked worsening of days with migraine and headache occurred in the washout period for those who got active treatment in the first period, whereas no such worsening in the washout period was seen among those who received placebo in the first period. The number of headache days in the washout period was significantly higher after active treatment than after placebo treatment (7.9 days vs. 5.8 days, $p=0.008$ ) (Fig. 2).
In the statistical analyses of potential carryover effect, we found that the order of treatment did not influence the efficacy of active treatment versus to the placebo period (Table 4). No significant difference in change of days per 4 weeks of migraine $(p=$ $0.35)$ or headache $(p=0.46)$ was found when comparing treatment sequence (active or placebo first) (Table 4).

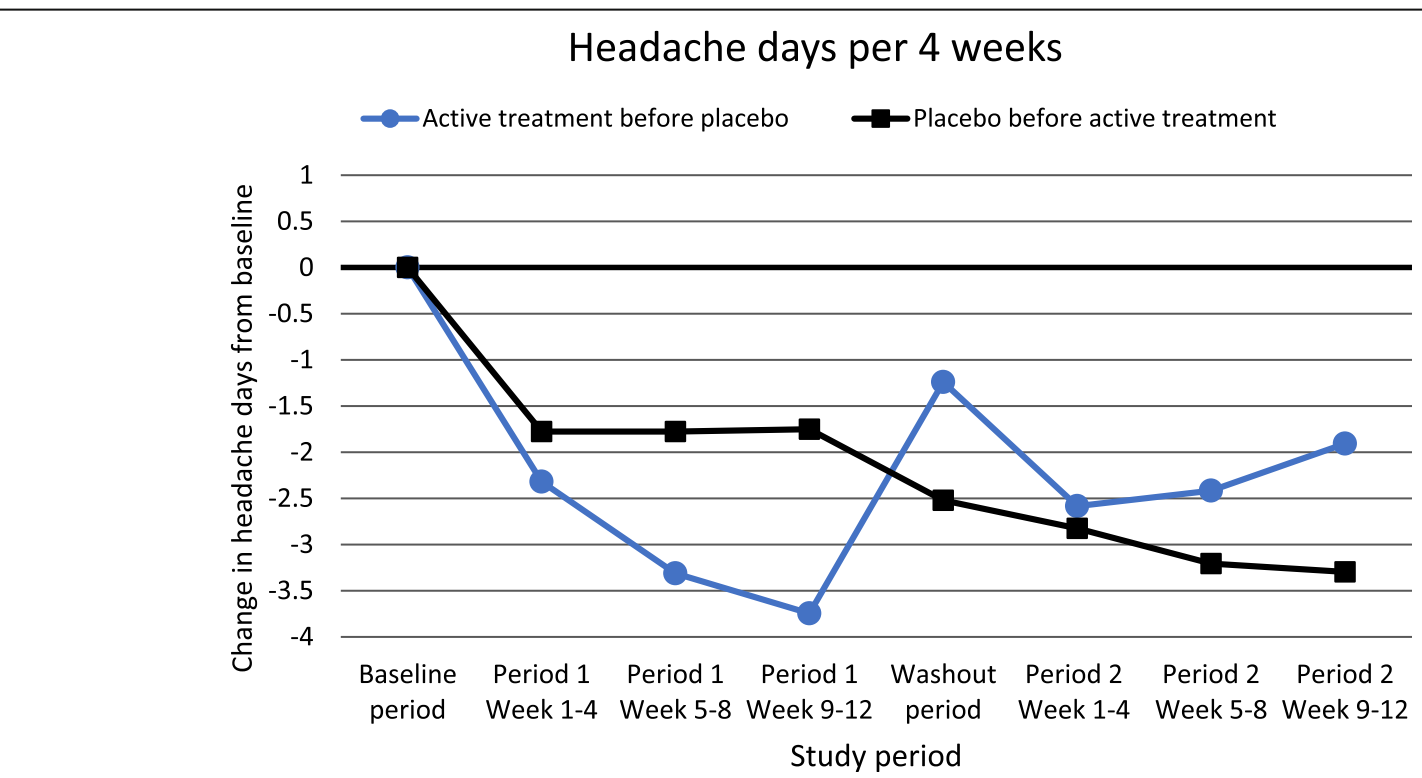

Fig. 2 Headache days per 4 weeks in relation to treatment sequence (square: Placebo first, $n=80$; circle: Active treatment first, $n=96$ ). Data from the study published in 2015 (the ALCAR-study) were omitted from this analysis due to lack of efficacy vs. placebo 
Table 4 Analyses of carry-over effect: effect of active treatment compared to placebo related to treatment sequence $(N=176)^{1}$

\begin{tabular}{lcll}
\hline Order of treatment & Number with complete data & $\begin{array}{l}\text { Change in migraine days/4 weeks, } \\
\text { mean }(95 \% \mathrm{Cl})\end{array}$ & $\begin{array}{l}\text { Change in headache days/4 weeks, } \\
\text { mean }(95 \% \mathrm{Cl})\end{array}$ \\
\hline Placebo before active treatment & 80 & $-0.90(-1.39,-0.40)$ & $-1.26(-1.95,-0.57)$ \\
Placebo after active treatment & 96 & $-1.22(-1.69,-0.74)$ & $-0.90(-1.58,-0.23)$ \\
P-value $^{2}$ & & 0.35 & 0.46 \\
\hline
\end{tabular}

'2001, 2003 and 2014 data included

${ }^{2}$ Evaluated by Student's t-test

\section{Discussion}

Using data from four crossover randomized trials evaluating preventive treatment in migraine, we found that the response to placebo treatment was consistent during follow-up, regardless of whether it came early or late in the study. Very few dropped out after the first period and no carryover effect was identified.

Crossover studies are not recommended in current guidelines for controlled trials of preventive treatment of chronic migraine owing to concerns over potential carryover effect, challenges with withdrawals, and fluctuation in treatment effect over time [6]. However, there is little documentation that these concerns are warranted, and the present study does, in our opinion, challenge these arguments. To the best of our knowledge, absence of carryover or period effect has not previously been clearly demonstrated in other cross-over studies evaluating migraine or other types of headache.

\section{Dropout rates}

A $9.8 \%$ dropout rate was observed during the $30-48$ weeks follow-up, the majority early in the first 12-week period. Overall, $79 \%$ of the participants completed the study per protocol. In comparison, a dropout rate of $4 \%$ was reported in a 22-week follow-up in a Norwegian placebo-controlled randomized crossover study of episodic migraine evaluating treatment with melatonin [18]. Moreover, in three crossover studies comparing two different active drug, dropout rates between $0 \%$ and 10\% \% were found [19-21]. In more recently published largescale RCTs with parallel group design, the proportion of dropouts have varied between 5.4-8.5\% during 12 weeks' treatment with calcitonin gene-related peptide (CGRP) antibodies [22-26], 8.5-13\% during 24 weeks' treatment with onabotulinumtoxin A $[27,28]$, and $31-46 \%$ during 26 weeks' treatment with topiramate [29-31]. Thus, the dropout rates in our studies with crossover design were not substantially higher than those in comparable and relatively recent parallel group studies [32]. The impression is confirmed by looking at a meta-analysis including more than 100 RCTs on migraine prevention from 1970. In this study mean dropout rates were almost identical for studies with crossover (21.2\%, SD 14.2, $n=59$ studies) and parallel group design (21.1\%, SD 14.0, $n=55$ studies) [32].

\section{Fluctuation in treatment effect over time}

The proportion of placebo responders was consistent during the follow-up period, being respectively $27-31 \%$ for migraine and $25-27 \%$ for headache. In comparison, previous meta-analyses have reported placebo responder rates in migraine preventives studies of respectively $21 \%$ (95\% CI 13-28\%) based on pooled data of 17 studies [4] and $22 \%$ (95\% CI 17-28\%) based on 26 studies [5]. The responder rate of active treatment in the present study was $47 \%$ for headache and $49 \%$ for migraine, somewhat higher than the mean of 26 studies showing a responder rate of migraine of $41 \%$ (95\% CI 37-45\%) [5]. One can argue that the consistent placebo-effect during the follow-up reported in our study, may be related to type of migraine patients included in these single center studies. In our opinion this explanation is less likely, but replication of the present results is needed.

\section{The possibility of a carryover effect}

A prolonged effect of active treatment that persists into the subsequent placebo period is called the carryover effect. If a long-lasting carryover effect had been present, one should have expected an extended period without worsening of migraine and headache, which is not seen (Figs. 1 and 2). It should be mentioned that the half-lives of candesartan, lisinopril and propranolol are very short (12 h or less), and most of the active drug will be eliminated during very few days [33-35]. Thus, most likely a potential long-lasting carryover effect would have to be caused by other mechanisms than a direct effect of the drug itself. However, in the present study we did not find evidence of a carryover effect. Firstly, the order of treatment did not influence the efficacy of active treatment versus placebo measured by change in number of days with headache and migraine per 4 weeks. Secondly, patients experienced a marked worsening when they entered the washout period after the active treatment period, whereas no such worsening was seen when placebo was given in the first period (Fig. 1). In fact, the number of headache days in the washout period was significantly higher after active treatment than after placebo treatment. Based on the present study, a washout-period of 4 weeks seems sufficient to eliminate the possibility of a carryover effect of candesartan, lisinopril and propranolol, and probably other drugs with short half-lives. 
Impact of placebo tablets in baseline and washout

Placebo tablets was used in baseline period and washout period in the two first studies. The main reason for such strategy was to eliminate prominent "placebo responders". There was, however, no difference in number of patients who had to be excluded from the study, owing to too few attacks depending on whether placebo was used during baseline or not. Furthermore, also in the washout period the use of placebo tablets did not have evident impact, because the increase in days with migraine and headache in the washout period after active treatment was even more marked when placebo tablets were given than when no tablets were given.

\section{Strengths and study limitation}

The number of withdrawals was low and proportion of completers high, probably caused by close follow-up by the study nurse. The design of the four studies was nearly similar, but not identical. We were able to investigate the influence of study differences by performing separate analyses for studies with and without use of placebo tablets in baseline and washout period. Furthermore, in the analyses of carryover effect, we excluded the study evaluating ALCAR because no effect of active treatment was found compared to placebo. However, in order to preserve the advantages by combined data, we did not separate regarding other (probably less important) methodological differences e.g. duration of followup. The present study only included drugs with short half-lives. Thus, we cannot rule out the possibility of a prominent carryover effect for drugs with much longer half-lives. The present study included 264 migraine patients in four single center RCTs, three trials evaluating antihypertensives and one ALCAR. However, it should be mentioned that generalization of the present results should be done with caution, because all studies were performed in one center, there were only four RCTs, and only three types of drugs were analyzed. The inclusion period of the four studies varied between 1.3-3 years [11-14]. Thus, because patients were included throughout the year, the potential effect of seasonal variation of migraine attacks was minimized.

\section{Crossover design: pro and cons}

The main advantage of the crossover design is that by allowing paired statistics it has much greater power than the parallel-group design, hence needing a much lower sample size. The crossover design is approximately eight times more powerful than parallel studies $[16,36]$. Hence, in the present four crossover studies between 60 and 72 patients were randomized [11-14]. In contrast, the corresponding number of randomized patients included in the parallel studies with CGRP antibodies have varied between 410 and 1130. This means that evaluation of new and promising preventive medicines in migraine, at least those with a short half-life, can be performed by single centers with RCT with a crossover design. Based on the present analyses, neither high dropout rate, carryover effect, or period effect seem to be valid arguments against RCT with crossover design in migraine prevention. This was true even for the double crossover study where participants were followed for nearly 1 year [13]. Interestingly, a gradually increasing effect of active medication is seen over the three months (Figs. 1 and 2). Thus, considering the low dropout rate in these studies, we suggest that longer treatment periods than 12 weeks could be considered in order to capture more long-term effects of preventive treatments."

\section{Conclusions}

By analyzing data from 264 adult migraine patients included in four crossover randomized trials evaluating preventive treatment, we found no period effect, no carryover effect and low dropout rates. For single centers, wishing to evaluate promising new preventive medication in adult migraine, we recommend RCTs with crossover design, at least for the early trials. Because treatment seemed to be most effective in the last 9-12 weeks, treatment periods longer than 12 weeks can be considered.

\section{Abbreviations \\ ALCAR: Acetyl-I-carnitine; CGRP: Calcitonin gene-related peptide; RCT: Randomized controlled trials; SD: Standard deviation}

\section{Authors' contributions}

$\mathrm{KH}$ and ABS: Study concept and design, collection of data, analysis and interpretation of data, writing of manuscript. LJS, ET, TS, GH, GBG: Interpretation of data, critical revision of manuscript. All authors read and approved the final manuscript.

\section{Funding}

This research received no specific grant from any funding agency in the public, commercial, or not-for-profit sectors.

Availability of data and materials

Part of the dataset supporting the conclusions of this article is available on request to the corresponding author.

Ethics approval and consent to participate

The present study (2017/2050/REK Midt) and all the four original studies were approved by the Regional Committee for Ethics in Medical Research. The two last studies were also approved by the Norwegian Medicines Agency (not needed for the two first studies). The participants have given written informed consent.

Consent for publication

Not applicable.

\section{Competing interests}

The authors declare that they have no competing interests.

\section{Author details}

'Department of Neuromedicine and Movement Science, Norwegian University of Science and Technology, 7489 Trondheim, Norway. ${ }^{2}$ Norwegian Advisory Unit on Headaches, St. Olavs University Hospital, Trondheim, Norway. ${ }^{3}$ Department of Neurology and Clinical Neurophysiology, St. Olavs 
University Hospital, Trondheim, Norway. ${ }^{4}$ Clinical Research Unit Central Norway, St. Olavs Hospital, Trondheim, Norway.

Received: 11 November 2019 Accepted: 15 December 2019 Published online: 27 December 2019

\section{References}

1. Lipton RB, Bigal ME, Diamond M, Freitag F, Reed ML, Stewart WF, AMPP Advisory Group (2007) Migraine prevalence, disease burden, and the need for preventive therapy. Neurology 68:343-349

2. Tfelt-Hansen P, Pascual J, Ramadan N, Dahlöf C, D'Amico D, Diener HC, International Headache Society Clinical Trials Subcommittee et al (2012) Guidelines for controlled trials of drugs in migraine: third edition A guide for investigators. Cephalalgia 32:6-38

3. Hougaard A, Tfelt-Hansen P (2016) General lack of use of placebo in prophylactic, randomised, controlled trials in adult migraine. A systematic review. Cephalalgia 36:960-969

4. Macedo A, Banos JE, Farre M (2008) Placebo response in the prophylaxis of migraine: a meta-analysis. Eur J Pain 12:68-75

5. Meissner K, Fässler M, Rücker G, Kleijnen J, Hróbjartsson A, Schneider A et al (2013) Differential effectiveness of placebo treatments: a systematic review of migraine prophylaxis. JAMA Intern Med 173:1941-195

6. Tassorelli C, Diener HC, Dodick DW, Silberstein SD, Lipton RB, Ashina M, International Headache Society Clinical Trials Standing Committee et al (2018) Guidelines of the International Headache Society for controlled trials of preventive treatment of chronic migraine in adults. Cephalalgia 38:815-832

7. Aby-Arafeh I, Hershey AD, Diener HC, Tassorelli C (2019) Guidelines of the international headache society for controlled trials of preventive treatment of migraine in children and adolescents, 1 st edition. Cephalalgia 39:803-816

8. Lewis JA (1987) Migraine trials: crossover or parallel group? Neuroepidemiology 6:198-208

9. Headache Classification Committee, Olesen J, Bousser MG, Diener HC, Dodick D, First M, Goadsby PJ et al (2006) New appendix criteria open for a broader concept of chronic migraine. Cephalalgia 26:742-746

10. Senn SJ (1992) Is the "simple carry-over" model useful? Stad Med 11:715-726

11. Schrader H, Stovner LJ, Helde G, Sand T, Bovim G (2001) Prophylactic treatment of migraine with angiotensin converting enzyme inhibitor (lisinopril): randomised, placebo controlled, crossover study. BMJ 322:19-22

12. Tronvik E, Stovner L, Helde G, Sand T, Bovim G (2003) Prophylactic treatment of migraine with an angiotensin $\|$ receptor blocker: a randomized controlled trial. JAMA 289:65-69

13. Stovner LJ, Linde M, Gravdahl GB, Tronvik E, Aamodt AH, Sand T et al (2013) A comparative study of candesartan versus propranolol for migraine prophylaxis: a randomised, triple-blind, placebo-controlled double crossover study. Cephalalgia 34:523-532

14. Hagen K, Brenner E, Linde M, Gravdahl GB, Tronvik EA, Engstrom M et al (2015) Acetyl---carnitine versus placebo for migraine prophylaxis: a randomized, triple-blind, crossover study. Cephalalgia 35:987-995

15. International Headache Society Committee on Clinical Trials in Migraine (1991) Guidelines for controlled trials of drugs in migraine: first edition. Cephalalgia 11:1-12

16. Tfelt-Hansen P, Block G, Dahlöf C, Diener HC, Ferrari MD, Goadsby PJ, International Headache Society Clinical Trials Subcommittee et al (2000) Guidelines for controlled trials of drugs in migraine: second edition. Cephalalgia 220:765-786

17. Sturdevant SG, Lumley T (2016) Testing for carryover effects after cessation of treatments: a design approach. BMC Med Res Methodol 16:92

18. Alstadhaug KB, Odeh F, Salvesen R, Bekkelund SI (2010) Prophylaxis of migraine with melatonin. A randomized controlled trial. Neurology 75: 1527-1532

19. Karimi N, Razian A, Heidari M (2019) The efficacy of magnesium oxide and sodium valproate in prevention of migraine headache: a randomized, controlled, double-blind, crossover study. Acta Neurol Belg. https://doi.org/ 10.1007/s13760-019-01101-x

20. Shaygannejad V, Janghorbani M, Ghorbani A, Ashtary F, Zakizade N, Nasr V (2006) Comparison of the effect of topiramate and sodium valporate in migraine prevention: a randomized blinded crossover study. Headache 46: 642-648

21. Gupta P, Singh S, Goyal V, Shukla G, Behari M (2007) Low-dose topiramate versus lamotrigine in migraine prophylaxis (the Lotolamp study). Headache 47:402-412
22. Goadsby PJ, Reuter U, Hallstrom Y, Broessner G, Bonner JH, Zhang F et al (2017) A controlled trial of Erenumab for episodic migraine. N Engl J Med 377:2123-2132

23. Sun H, Dodick DW, Silberstein S, Goadsby PJ, Reuter U, Ashina M et al (2016) Safety and efficacy of AMG 334 for prevention of episodic migraine: a randomised, double-blind, placebo-controlled, phase 2 trial. Lancet Neurol 15:382-390

24. Silberstein SD, Dodick DW, Bigal ME, Yeung PP, Goadsby PJ, Blankenbiller T et al (2017) Fremanezumab for the preventive treatment of chronic migraine. N Engl J Med 377:2113-2122

25. Skljarevski V, Oakes TM, Zhang Q, Ferguson MB, Martinez J, Camporeale A et al (2018) Effect of different doses of Galcanezumab vs placebo for episodic migraine prevention: a randomized clinical trial. JAMA Neurol 75: 187-189

26. Dodick DW, Ashina M, Brandes JL, Kudrow D, Lanteri-Minet M, Osipova V et al (2018) ARISE: a phase 3 randomized trial of erenumab for episodic migraine. Cephalalgia 38:1026-1037

27. Aurora SK, Dodick DW, Turkel CC, DeGryse RE, Silberstein SD, Lipton RB et al (2010) PREEMPT 1 chronic migraine study group. OnabotulinumtoxinA for treatment of chronic migraine: results from the double-blind, randomized, placebo-controlled phase of the PREEMPT 1 trial. Cephalalgia 30:793-803

28. Diener HC, Dodick DW, Aurora SK, Turkel CC, DeGryse RE, Lipton RB et al (2010) PREEMPT 2 chronic migraine study group. OnabotulinumtoxinA for treatment of chronic migraine: results from the double-blind, randomized, placebo-controlled phase of the PREEMPT 2 trial. Cephalalgia 30:804-814

29. Diener HC, Tfelt-Hansen P, Dahlöf C, Láinez MJ, Sandrini G, Wang SJ et al (2004) MIGR-003 study group. Topiramate in migraine prophylaxis--results from a placebo-controlled trial with propranolol as an active control. J Neurol 251:943-950

30. Silberstein SD, Neto W, Schmitt J, Jacobs D, MIGR-001 Study Group (2004) Topiramate in migraine prevention: results of a large controlled trial. Arch Neurol 61:490-495

31. Brandes JL, Saper JR, Diamond M, Couch JR, Lewis DW, Schmitt J et al (2004) Topiramate for migraine prevention: a randomized controlled trial. JAMA 291:965-973

32. Jackson JL, Cogbill E, Santana-Davila R, Eldredge C, Collier W, Gradall A et al (2015) A comparative effectiveness meta-analysis of drugs for the prophylaxis of migraine headache. PLoS One 10:e0130733

33. Toutain PL, Lefèbvre HP (2004) Pharmacokinetics and pharmacokinetic/ pharmacodynamic relationships for angiotensin-converting enzyme inhibitors. J Vet Pharmacol Ther 27:515-525

34. Hübner R, Högemann AM, Sunzel M, Riddell JG (1997) Pharmacokinetics of candesartan after single and repeated doses of candesartan cilexetil in young and elderly healthy volunteers. J Hum Hypertens 11(Suppl 2):S19-S25

35. Shand DG (1976) Pharmacokinetics of propranolol: a review. Postgrad Med 52(Suppl 4):22-25

36. Tfelt-Hansen P, Nielsen SL (1987) Patient numbers needed in prophylactic migraine trials. Neuroepidemiology 6:214-219

\section{Publisher's Note}

Springer Nature remains neutral with regard to jurisdictional claims in published maps and institutional affiliations.

Ready to submit your research? Choose BMC and benefit from:

- fast, convenient online submission

- thorough peer review by experienced researchers in your field

- rapid publication on acceptance

- support for research data, including large and complex data types

- gold Open Access which fosters wider collaboration and increased citations

- maximum visibility for your research: over $100 \mathrm{M}$ website views per year

At BMC, research is always in progress.

Learn more biomedcentral.com/submission 